\title{
Effects of physical-cognitive training on physical and psychological functions among older adults with type 2 diabetes and balance impairment: a randomized controlled trial
}

\author{
Ratchanok Kraiwong ${ }^{1, *}$, Mantana Vongsirinavarat', Maliwan Rueankam², Thanayot Sumalrot ${ }^{3}$ \\ 'Department of Physical Therapy, Faculty of Physical Therapy, Mahidol University, Nakhon Pathom, Thailand \\ 2Department of Occupational Therapy, Faculty of Physical Therapy, Mahidol University, Nakhon Pathom, Thailand \\ ${ }^{3}$ Department of Psychiatry, Faculty of Medicine Siriraj Hospital, Mahidol University, Bangkok, Thailand
}

Risks of falls among older adults are multifactorial in nature. A combined training program might be beneficial on fall-related outcomes. This study aimed to explore the effects of group-based physical-cognitive trainings on physical and psychological outcomes among older adults with type 2 diabetes mellitus (T2DM) and balance impairment. Fall incidence were also determined. Thirty-seven older adults with T2DM and balance impairment were randomly assigned to control and intervention groups. The intervention program comprised of 24 training sessions of 45-60 min exercise for 8 weeks. The exercise consisted of warm-up, aerobic exercise by nine square stepping, resistance exercise combined with cognitive training and cool down. All participants were assessed at baseline, 4 and 8 weeks after intervention, and 1-year follow-up. Both groups reported similar rates of falls. Global cognition, depressive symptoms, and fear of falling did not differ between groups at any time. The Timed Up \& Go (TUG) test, alternate stepping test (AST), knee extensors, ankle plantarflexors, and dorsiflexors strength differed at 4 weeks. TUG, AST, hip abductors, knee flexors, ankle plantarflexors, and dorsiflexors strength differed at 8 weeks. The activity of daily living (ADL), TUG test $(P=0.002)$ and AST, hip extensors and abductors, knee extensors and flexors, ankle plantarflexors and dorsiflexors were different at 1-year follow-up. The group-based physical-cognitive training could benefit older adults with T2DM in terms of maintaining ADL. The intervention could reduce fall risk factors by improving balance and lower limb muscle strength among older adults with T2DM and balance impairment.

Keywords: Exercise, Balance, Muscle strength, Cognition, Falls

\section{INTRODUCTION}

Diabetes mellitus (DM) is a worldwide, epidemic health condition. This chronic condition reportedly increases the risk of falling by $64 \%$ among older people (Yang et al., 2016). This higher risk was due to degenerated physical and cognitive functions associated with age-related declines and disease-related complications (Vinik et al., 2015). The physical impairments leading to gait and balance disorders as well as muscle weakness are commonly experienced in older adults with type 2 DM (T2DM) (Yang et al., 2016). More- over, the psychological aspects related to fall including cognitive impairment, depression, and fear of falling were also observed (Hewston and Deshpande, 2016; Vinik et al., 2015; Yang et al., 2016).

Many forms of physical exercises and balance training had been proposed as the key interventions to improve falls-related outcomes among older adults with T2DM (Chapman et al., 2017). However, the effectiveness was various in studies depending on the interventions and outcomes measured. For example, large effect on falls prevention was reported by reducing $39 \%$ of falls rate in older
${ }^{*}$ Corresponding author: Ratchanok Kraiwong (iD https://orcid.org/0000-0002-9533-7348 Department of Physical Therapy, Faculty of Physical Therapy, Mahidol University, Phuttamonthon, Nakhon Pathom, Thailand

Email: ratchanok.tha@mahidol.edu

Received: February 5, 2021 / Accepted: February 25, 2021
This is an Open Access article distributed under the terms of the Creative Commons Attribution Non-Commercial License (https://creativecommons.org/licenses/by-nc/4.0/) which permits unrestricted non-commercial use, distribution, and reproduction in any medium, provided the original work is properly cited. 
adults if using exercises with moderate to high challenges to balance (Sherrington et al., 2017). However, the falls rate, functional performance according to Berg Balance and Timed Up \& Go (TUG) tests and ankle muscle strength were not different between the groups receiving lower-extremity exercise and walking training compared with control (Kruse et al., 2010).

Physical exercise also had effect on cognitive function which typically impaired in older adults with T2DM. Physical activity intervention including walking, resistance training, and flexibility exercises improved cognitive and gait performances in older adults with T2DM (Espeland et al., 2017). A meta-analysis showed small to moderate effect sizes of aerobic and multimodal exercises on the cognitive function improvement in people with T2DM (Cooke et al., 2020).

Although the balance training could evidently prevent falls (Sherrington et al., 2017), this type of training alone did not improve the dual-tasks ability of walking with other activities which were needed for activity of daily living (ADL) and social participating in older people (Silsupadol et al., 2009). Therefore, the combining physical and cognitive trainings might be more appropriate especially those at risk of falls (Fisseha et al., 2017). The older adults receiving combined trainings of dual-task and phonemic verbal fluency practice had greater improvements of gait parameters compared with group receiving only the physical exercise (Boa Sorte Silva et al., 2018a). The cognitive combined with physical trainings could improve the TUG cognition and global cognition (Htut et al., 2018). Physical trainings along with the social engagement promotion were also shown to improve mobility and cognition among older adults with subjective cognitive complaints (Boa Sorte Silva et al., 2018a; Boa Sorte Silva et al., 2018b).

Combined physical and cognitive trainings were clearly benefit the mobility and cognition in older adults. However, there are still limited evidences for group-based combined physical and cognitive training on falls-related outcomes and falls rate, especially ones with balance impairment. Therefore, this study aimed to explore the effects of group-based physical and cognitive trainings for 24 sessions concerning physical, psychological functions, ADL, and falls rate among older adults with T2DM and balance impairment.

\section{MATERIALS AND METHODS}

This study was a double-blind, randomized control trial. The randomization was cluster sampling of residential areas, to allocate older adults in the intervention and control groups. The study was registered with ClinicalTrials.gov (TCTR20180119001) and eth- ically approved by the Mahidol University Central Institutional Review Board (No. MU-CIRB 2018/005.0801).

\section{Participants}

Two hundred twenty-three ( $\mathrm{n}=223)$ community-dwellers with T2DM living in Nakhon Pathom, Thailand were enrolled in this study. To be included, participants had to be older adults aged $\geq 60$ years, diagnosed of T2DM. They also had impairment of functional balance identified by the TUG with a time greater than $10 \mathrm{sec}$. The exclusion criteria included having history of (a) central nervous system dysfunction as stroke or Parkinson disease, (b) lower limb amputation or joint replacement, (c) lumbar or lower limb fracture or surgery within the previous 6 months, (d) significant pain or symptoms of musculoskeletal disorders affecting movements during walking and balance assessments, and (e) unsafe blood pressure for exercise ( $>180 / 100$ or $<100 / 60 \mathrm{mmHg}$ during resting). After screening, 37 participants were eligible and allocated to control $(n=15)$ and intervention $(n=22)$ groups (Fig. 1).

\section{Intervention}

Four registered physical therapists were trained to provide the intervention according to the standardized protocol. During the intervention period, the therapists kept a daily record to monitor blood pressure, heart rate, Borg Rating of Perceived Exertion, and the progress and responses of each participant.

\section{Exercise intervention}

Group-based, physical-cognitive exercises with 6 to 12 participants per group were held in the community. The intervention combined moderate-intensity exercise (Colberg et al., 2016) and cognitive training. Each session took 45 to $60 \mathrm{~min}$ for 3 sessions in a week. The period of program was 8 weeks, totaling 24 exercise sessions. The exercise included physical exercises (aerobics, strengthening, and balance training) and cognitive trainings (memory, attention, and executive functions). The exercise protocol consisted of four sections: a warm-up, an aerobics training with nine squares stepping exercise (9SSE) (Outayanik et al., 2017), strengthening exercises combined with cognitive training and a cool-down period. The warm-up session involved $10 \mathrm{~min}$ of light aerobic with a dynamic range of motion exercises of the neck, trunk, upper and lower extremities. The physical exercises were $25 \mathrm{~min}$ of the large rhythmical activity by 9SSE at moderate to vigorous intensity (Colberg et al., 2016) with the Borg Rating of Perceived Exertion of 5 to 8 on a scale from 0 to10. To progress to the next level of the 9SSE activity, all participants were required to perform cor- 


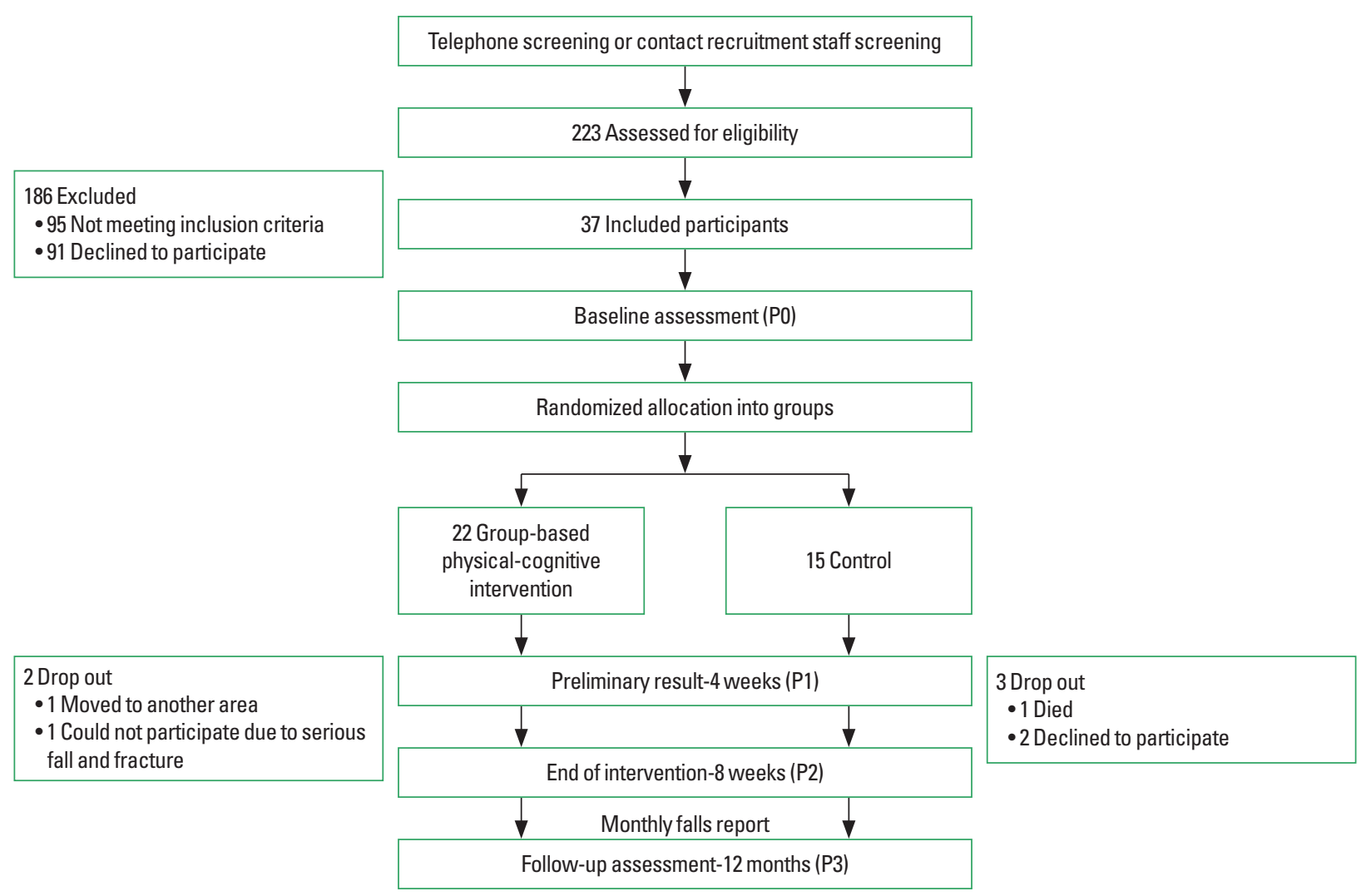

Fig. 1. Study flow.

rectly at least 4 times of each walking pattern in each round of exercise (Boa Sorte Silva et al., 2018a; Boa Sorte Silva et al., 2018b). For the continuing exercise session, the group had to start from pattern 1 to the last pattern, and then adding the progression pattern. The resistance exercise and cognitive training session were held for 10 to $15 \mathrm{~min}$, combining low intensity-exercise with cognitive trainings (memory, attention, and executive functions). The subsections of each week comprised of day 1: resistive band of upper extremity and chair exercises combined with adding and subtracting numbers training, day 2: resistive band of lower extremity and chair exercises with episodic memory and visuospatial working memory training, and day 3: core strengthening using a gym ball with attention, flexibility and semantic fluency training. The cool down was for 10 min of light aerobics: stretching and breathing exercises, performed at the end of every section. Vital signs and Borg Rating of Perceived Exertion were constantly monitored before, during and after the exercise sessions. During the activities challenging balance, the therapists guarded the participant to prevent falling.

\section{Control group intervention}

The control group participated in 4 sessions of health education throughout the data collection period. The contents including diet, exercise, and fall prevention recommendations were provided by interactive lectures.

\section{Outcome measures}

All outcome assessments were conducted in the community. The registered physical therapists responsible for data collection were trained. Before the data collection, the intertester and intratester reliabilities were tested. All assessors were blinded to the group allocation. The demographic data collected included age, sex, educational levels, history of falls within the previous 6 months, medical history, weight, height, body mass index, resting heart rate, resting blood pressure, orthostatic hypotension, the Michigan Neuropathy Screening Instrument (Feldman et al., 1994), fasting blood sugar, and hemoglobin A1c. The baseline outcome assessment (P0) included four domains of physical functions, cognitive functions, mental status, and ADL. The schedule of outcome assessments in the follow-up periods is presented in Fig. 1. 


\section{Physical function}

Balance performance was assessed using the TUG and alternate step test (AST). For the TUG, the participants sat on a $43-\mathrm{cm}$ height armchair with their back on the chair back support. They were asked to perform the TUG as quickly and safely as possible (Shumway-Cook et al., 2000). One practice trial was allowed. Two test trials were performed with at least 2-min rest between the trials. The result of the better performance was used (ShumwayCook et al., 2000). For AST, the participants stood on the floor with barefooted. They were asked to alternately step as fast as possible for eight steps on a 19-cm height and 40-cm depth step (Tiedemann et al., 2008). One practice trial was allowed. The AST was tested twice with 2 min rest between the tests. The value representing the best AST was used. The strength of lower limb muscle groups including hip (flexors, extensors, and abductors), knee (flexors and extensors), and ankle (plantarflexors and dorsiflexors) were measured using a handheld dynamometer (Mentiplay et al., 2015). All muscle groups were tested in midrange of joint motion. One practice trial was given before measuring each movement. The average of three trials was recorded for each muscle group. To perform the Five-Times-Sit-to-Stand Test (FTSST), participants were asked to sit on a standard height chair without armrests. They were asked to complete the FTSST as fast as possible with arms crossed (Tiedemann et al., 2008). The FTSST was tested twice with 2-min rest in between. The better performance was used.

\section{Psychological outcomes}

Global cognition was assessed using the Montreal Cognitive Assessment (Pinto et al., 2019). One point score is added for the participants with education $\leq 6$ years. Depressive symptoms were screened using Patient Health Questionnaire-9. The test comprises a self-report questionnaire of depressive symptoms (Lotrakul et al., 2008). Fear of falling was assessed using the Thai version of the Fall Efficacy Scale-International. This tool is used to assess concerns related to physical and social activities (Thiamwong and Suwann, 2014).

\section{Activity of daily living}

The Barthel Index is a validated scale measuring for ADL with higher scores indicating greater independence (Mahoney and Barthel, 1965).

\section{Fall history and falls rate}

History of falls was documented over the previous 6 months. Monthly falls rate was documented during the intervention for 2 and 12 months after the intervention period. Fall was defined as an event resulting a person in coming to rest inadvertently on the ground or floor or other lower level (World Health Organization, 2007). The history of falls in the study might have derived from postural hypotension as dizziness while standing up, vertigo, dizziness while squeezing urine/feces, stumbling over objects, losing balance while changing posture, tripping, slipping, stumbling at different levels or on steps, falling down stairs, weakness or blurred vision.

\section{Data analysis}

The intention-to-treat analysis was adopted (White et al., 2011) in this study. The data of participants unavailable for follow-up and who either withdrew or dropped out were included in the original group allocated. Using the last observation carried forward approach, the final results measured before the participant's dropout was applied in all the following data points. When participants dropped out from the study after measuring the baseline information and were not evaluated again, the baseline was used as the results throughout the study. In the case of dichotomous results, and all follow-up data of the control group were assumed the best, i.e., not falling, while the intervention group was assumed the worst as falling.

Statistical analysis was performed using statistical software package SPSS ver. 18 (SPSS Inc., Chicago, IL, USA). The KolmogorovSmirnov Goodness of Fit Test was used to test the distribution of the data. One-way analysis of variance (ANOVA) was used to assess demographic data, health information, and baseline outcomes among groups. For continuous variables, the homogeneity of variance was performed using Levene test. Binary logistic regression was conducted to evaluate the relation between the intervention group and falls. Two-way mixed-design ANOVA with Bonferroni corrections was performed to analyze the main effects of the groups, time and the interaction. Partial eta squared determined effect size of the significant effects. The value of $P<0.05$ was considered statistically significant.

\section{RESULTS}

The characteristics of the participants in both groups were not different (Table 1). However, differences were observed for the global cognition and knee extensors strength at baseline. These two variables were therefore treated as covariates in the analysis.

There were interactions between groups and times for TUG, AST, strength of hip, knee, and ankle muscles as shown in Table 2. 
Compared with the control, these physical performance outcomes of the intervention group were improved significantly at 4 and/or

Table 1. Characteristics of older adults with T2DM $(n=37)$

\begin{tabular}{lccc}
\hline Characteristic & Control $(\mathrm{n}=15)$ & Exercise $(\mathrm{n}=22)$ & $P$-value \\
\hline Sex, female:male & $14: 1$ & $15: 7$ & \\
Age $(\mathrm{yr})$ & $72.87 \pm 6.42$ & $70.09 \pm 4.45$ & 0.129 \\
Duration of DM (yr) & $12.87 \pm 5.66$ & $15.41 \pm 10.22$ & 0.388 \\
MNSI (score) & $1.67 \pm 1.34$ & $1.50 \pm 1.25$ & 0.702 \\
Orthostatic hypotension & 0 & 0 & \\
FBS (mg/dL) & $151.87 \pm 46.62$ & $161.73 \pm 64.88$ & 0.616 \\
HbA1c $(\%)$ & $7.67 \pm 176$ & $8.49 \pm 1.82$ & 0.172 \\
Body mass index $\left(\mathrm{kg} / \mathrm{m}^{2}\right)$ & $24.18 \pm 3.78$ & $24.44 \pm 3.38$ & 0.828 \\
Falls history $(\%)$ & 6.7 & 4.5 & 0.787
\end{tabular}

Values are presented as number or mean \pm standard deviation.

T2DM, type 2 diabetes mellitus; DM, diabetes mellitus; MNSI, Michigan Neuropathy Screening Instrument; FBS, fasting blood sugar; HbA1c, hemoglobin A1c (glycated hemoglobin).
8 weeks (Fig. 2). At 1 year, the intervention group had better ADL performance scores (Fig. 3), TUG, and AST (Fig. 2) compared with the control group. The strength of all muscle groups except hip flexors also significantly differed between groups (Fig. 2). No differences were observed between groups at four and 8 weeks for the ADL score and the psychological outcomes including the Montreal Cognitive Assessment, Patient Health Questionnaire-9, and Fall Efficacy Scale-International (Fig. 3). Falls history in the previous 6 months (Table 1 ) and the falls rate along the follow-up period were the same between groups (Fig. 3). No adverse events such as falls, or other injuries were observed during the exercise sessions and data collection.

Among times assessed, the intervention group had significantly longer TUG at baseline compared with 4 weeks $(P<0.001)$, 8 weeks $(P<0.001)$, and 1 year $(P<0.001)$. The AST at baseline was significantly longer compared with $4(P=0.008)$ and 8 weeks $(P=0.001)$. The FTSST at baseline was significantly longer com-

Table 2. Comparison of anthropometric, hemodynamic data, cognitive function, depression symptoms, fear of falling, activity of daily living, balance, and muscle strength between groups $(n=37)$

\begin{tabular}{|c|c|c|c|c|c|c|c|c|c|}
\hline \multirow{2}{*}{ Parameter } & \multicolumn{3}{|c|}{ Group } & \multicolumn{3}{|c|}{ Time } & \multicolumn{3}{|c|}{ Group x time interaction } \\
\hline & $F(d f)$ & $P$-value & Effect size & $F(d f)$ & $P$-value & Effect size & $F(d f)$ & $P$-value & Effect size \\
\hline \multicolumn{10}{|l|}{ Characteristic } \\
\hline FBS (mg/dL) & $0.003(1,35)$ & 0.959 & $<0.001$ & $0.27(1,35)$ & 0.610 & 0.008 & $1.48(1,35)$ & 0.232 & 0.041 \\
\hline $\mathrm{HbA1c}(\%)$ & $0.20(1,35)$ & 0.198 & 0.047 & $0.82(1,35)$ & 0.371 & 0.023 & $0.58(1,35)$ & 0.581 & 0.009 \\
\hline $\mathrm{BMl}$ & $0.11(1,35)$ & 0.741 & 0.003 & $0.65(1.5,52.6)$ & 0.483 & 0.180 & $2.19(1.5,52.6)$ & 0.134 & 0.059 \\
\hline \multicolumn{10}{|l|}{ Psychological function } \\
\hline $\begin{array}{l}\text { Global cognition (MoCA) (MoCA at } \\
\mathrm{PO}=\text { covariate) }\end{array}$ & $0.02(1,34)$ & 0.893 & 0.001 & $0.94(2,68)$ & 0.396 & 0.027 & $1.25(2,68)$ & 0.293 & 0.035 \\
\hline Depression (PHO-9) & $2.86(1,35)$ & 0.100 & 0.075 & $1.97(3,105)$ & 0.124 & 0.053 & $1.18(3,105)$ & 0.322 & 0.033 \\
\hline Fear of falling (FES-I) & $2.77(1,35)$ & 0.105 & 0.073 & $2.75(2.7,92.8)$ & 0.054 & 0.073 & $1.17(2.7,92.8)$ & 0.323 & 0.032 \\
\hline ADL (Barthel Index) & $6.15(1,35)$ & $0.018^{*}$ & 0.149 & $1.31(3,105)$ & 0.276 & 0.036 & $2.71(3,105)$ & $0.049^{*}$ & 0.072 \\
\hline \multicolumn{10}{|l|}{ Physical performance } \\
\hline \multicolumn{10}{|l|}{ Balance performance } \\
\hline TUG (s) & $8.40(1,35)$ & $0.006^{*}$ & 0.194 & $16.05(2.8,99.7)$ & $<0.001^{*}$ & 0.314 & $12.56(2.8,99.7)$ & $<0.001^{*}$ & 0.264 \\
\hline AST (s) & $6.43(1,35)$ & $0.016^{*}$ & 0.155 & $9.77(2.4,85.3)$ & $<0.001^{*}$ & 0.218 & $2.94(2.4,85.3)$ & $0.048^{*}$ & 0.007 \\
\hline \multicolumn{10}{|l|}{ Muscle strength } \\
\hline FTSST (s) & $0.23(1,35)$ & 0.633 & 0.007 & $7.38(2.5,87.3)$ & $<0.001^{*}$ & 0.174 & $1.99(2.5,87.3)$ & 0.132 & 0.054 \\
\hline Hip extensors & $4.99(1,350$ & $0.032^{*}$ & 0.125 & $1.27(3,105)$ & 0.290 & 0.035 & $3.78(3,105)$ & $0.013^{*}$ & 0.097 \\
\hline Hip flexors & $4.01(1,35)$ & 0.053 & 0.103 & $4.65(3,105)$ & $0.004^{*}$ & 0.117 & $1.29(3,105)$ & 0.281 & 0.036 \\
\hline Hip abductors & $4.94(1,35)$ & $0.033^{*}$ & 0.124 & $0.91(3,105)$ & 0.437 & 0.025 & $1.22(3,105)$ & 0.307 & 0.034 \\
\hline Knee extensors ( $\mathrm{KE}$ at $\mathrm{PO}=$ covariate) & $7.05(1,34)$ & $0.012^{*}$ & 0.172 & $0.24(1.7,67.4)$ & 0.752 & 0.007 & $0.21(1.7,67.4)$ & 0.771 & 0.006 \\
\hline Knee flexors & $6.03(1,35)$ & $0.019^{*}$ & 0.147 & $1.64(1.8,62.0)$ & 0.205 & 0.450 & $0.50(1.8,62.0)$ & 0.588 & 0.014 \\
\hline Ankle plantarflexors & $13.75(1,35)$ & $0.001^{*}$ & 0.282 & $3.50(2.04,71.5)$ & $0.035^{*}$ & 0.091 & $1.79(2.04,71.5)$ & 0.173 & 0.049 \\
\hline Ankle dorsiflexors & $17.89(1,35)$ & $<0.001^{*}$ & 0.338 & $2.09(2.6,92.7)$ & 0.114 & 0.056 & $0.94(2.6,92.7)$ & 0.415 & 0.026 \\
\hline
\end{tabular}

DM, diabetes mellitus; FBS, fasting blood sugar; HbA1c, hemoglobin A1c (glycated hemoglobin); ADL, activity of daily living; MoCA, Montreal Cognitive Assessment; PHQ-9, Patient Health Questionnaire-9; FES-I, Fall Efficacy Scale-International; TUG, Timed Up \& Go test; AST, alternate step test; FTSST, Five-Times-Sit-to-Stand Test; KE, knee extensors; PO, baseline.

${ }^{*} P$-value $<0.05$ significant difference pairwise compared with control group at the same time. 

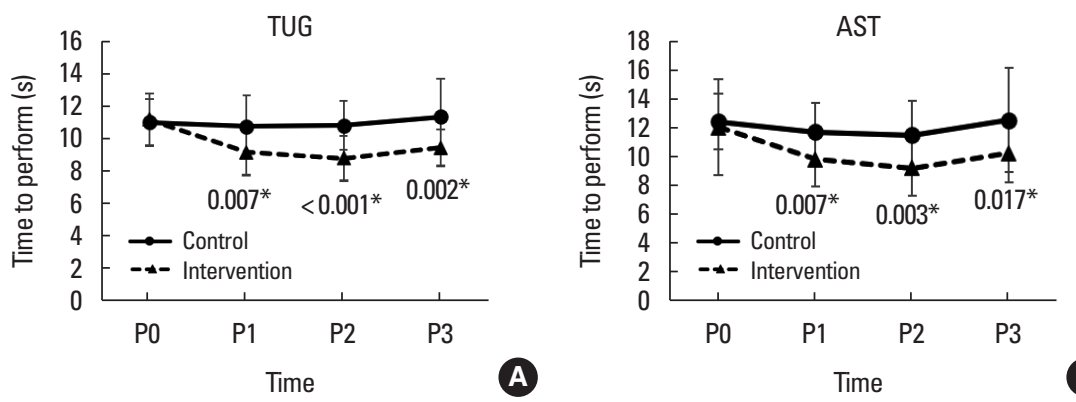

B
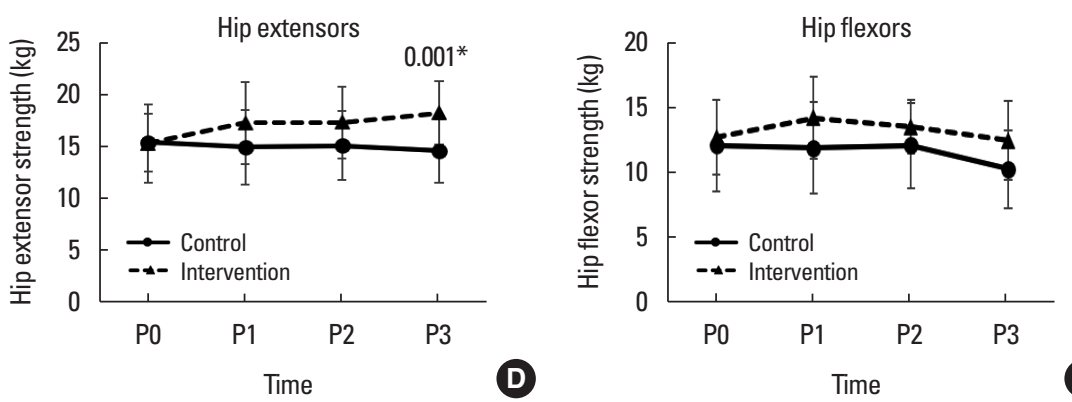

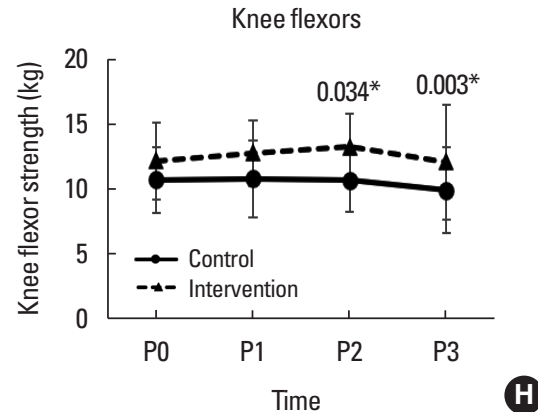

(H)

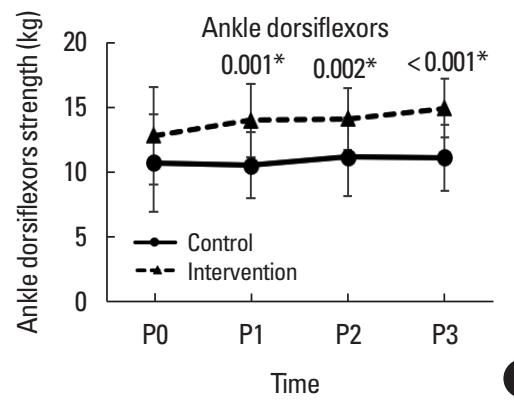

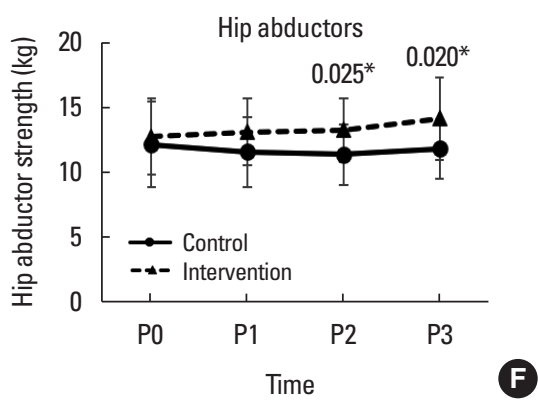

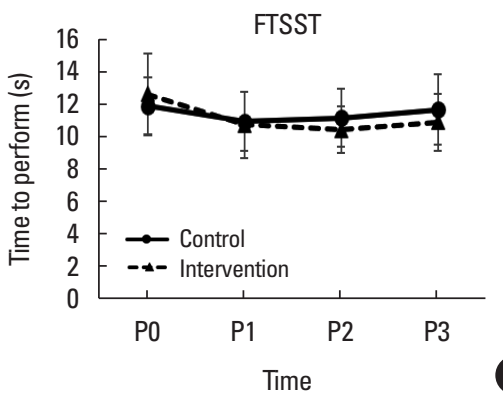

C

Fig. 2. The physical performance between older adults with T2DM. The line graphs of physical performance as balance and muscle strength between older adults with T2DM were demonstrated. Time to complete the TUG (A) and AST (B) were illustrated. The strength of the FTSST (C), hip extensors (D), hip flexors (E), hip abductors $(F)$, knee extensors $(G)$, knee flexors $(H)$, plantarflexors (I), and ankle dorsiflexors (J) were demonstrated. T2DM, type 2 diabetes mellitus, TUG, Timed Up \& Go test; AST, alternate step test; FTSST, Five-Times-Sit-to-Stand Test; P0, baseline; P1, 4 weeks; P2, 8 weeks; P3, 1 year after intervention. ${ }^{*} P<0.05$ showed significant difference pairwise compared with control group at the same time. pared with 8 weeks $(P=0.006)$. Hip extensor strength at baseline significantly differed compared with 1 year $(P=0.002)$. Hip flexor strength at baseline significantly differed compared with 4 weeks $(P=0.032)$. Ankle plantarflexor $(P=0.003)$ and dorsiflexor $(P=$ $0.045)$ strength at baseline significantly differed compared with 1 year.

All psychological outcomes of the control group were not dif- ferent except the global cognition. The control group exhibited significant differences of the global cognition at 4 weeks $(P \leq 0.001)$, 8 weeks $(P \leq 0.001)$, and 1 year $(P \leq 0.001)$ compared with those of baseline. The intervention group also had significant differences of global cognition at 8 weeks $(P=0.030)$ and 1 year compared $(P=0.016)$ with the baseline. 

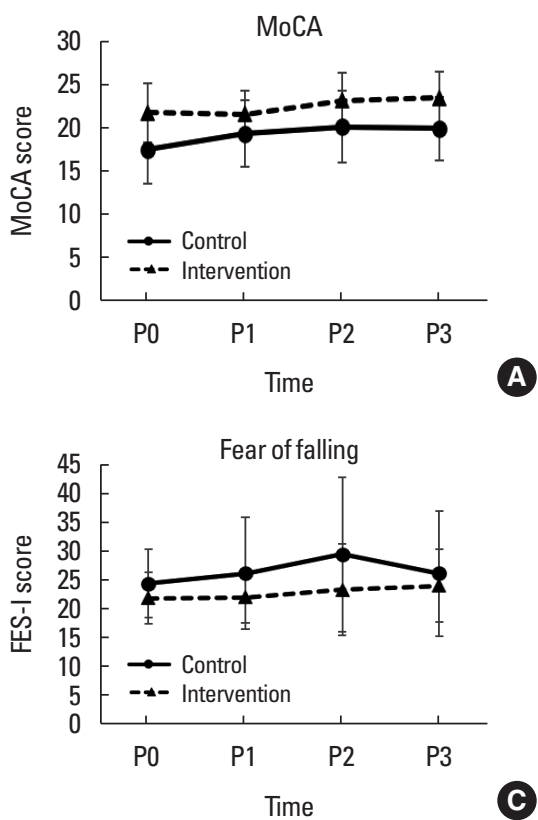
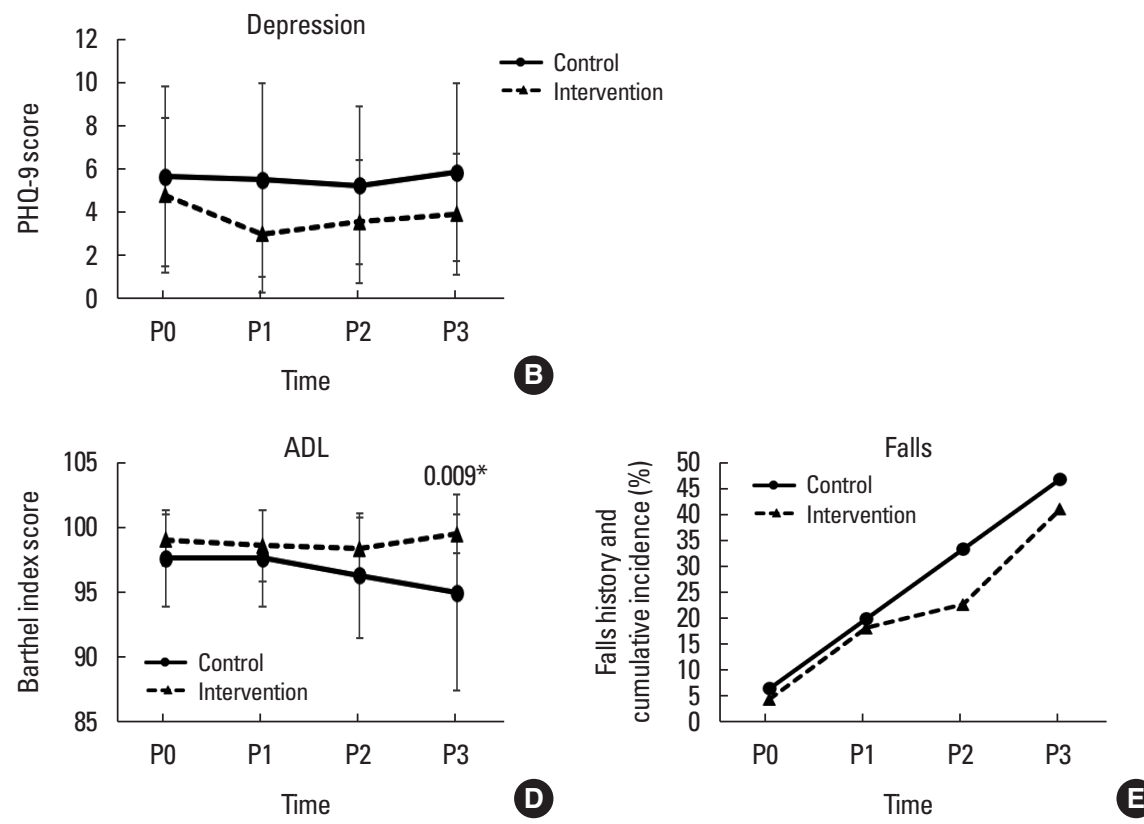

Fig. 3. The psychosocial function and ADL between older adults with T2DM. The line graphs of psychosocial function and ADL between older adults with T2DM were demented. The psychosocial function, global cognition (A), depressive symptoms (B), fear of falling (C), $A D L(D)$, and fall history and cumulative incidence (E) between older adults with T2DM were demonstrated. ADL, activity of daily living; T2DM, type 2 diabetes mellitus; MoCA, Montreal Cognitive Assessment; PHQ-9, Patient Health Questionnaire-9; FES-I, Fall Efficacy Scale-International; P0, baseline; P1, 4 weeks; P2, 8 weeks; P3, 1 year after intervention. ${ }^{*} P<0.05$ showed significant difference pairwise compared with control group at the same time.

\section{DISCUSSION}

This study showed beneficial effects of the combined training program on the physical outcomes and ADL. However, the intervention did not bring about significant improvement of psychological outcomes and falls rate.

Aerobics, resistance, and balance exercise were evidently valuable and are commonly recommended as exercise interventions for T2DM (Colberg et al., 2016). The intervention in this study consisted of aerobic exercise of the large rhythmical activity by 9SSE and resistance exercise combined with cognitive training. The results, in line with the previous studies (Colberg et al., 2016; Lee et al., 2017; Nomura et al., 2018), suggested that these trainings could improve lower limb muscle strength among older adults with T2DM and balance impairment. Specifically, moderate- or high-intensity resistance exercise has been reported as an effective mean to improve strength and physical function among older people with T2DM (Lee et al., 2017; Nomura et al., 2018). Resistance training is suggested as the counter measure for aging-associated muscle weakness, attesting to reduce markers of oxidative stress and improve mitochondrial function (Tarnopolsky, 2009). The enlarged cross-sectional area of type I and II muscle fibers was also found after 16 weeks of strengthening exercise combined with standard care among older adults with T2DM (Brooks et al., 2006). The increases in strength and muscle mass were mediated mainly via muscle hypertrophy and neuromuscular remodelling (Strasser and Pesta, 2013).

This study found no differences of the FTSST between groups. The hip extension range of motion and knee extensor strength have been shown as the predictors of FTSST (Jung and Yamasaki, 2016). In previous study, 12-week leg exercise program could improve muscle strength as identified by FTSST in older people with T2DM (Hiengkaew et al., 2015). The significant improve of FTSST and knee range of motion were found for once-weekly balance retraining and leg strengthening and endurance exercises for 8 weeks in adults age 40-79 years old, with DM and DNP (Venkataraman et al., 2019). However, the different contents of program, duration of exercise, and age range might be the factors relating to the different results. Moreover, the range of motion of the lower extremity was not assessed in our study which limited the supposition of the intervention concerning FTSST.

Balance and resistance training could also improve balance and reaction time among older people with T2DM (Morrison et al., 2010). The 9SSE exhibited benefit for balance among older adults 
(Outayanik et al., 2017). The intervention group who practiced 9SSE in this study had better balance performances identified by TUG and AST compared with the control at all periods of time.

The improved muscle strength in the intervention group might be the reason for the improved balance performances among participants in this study. The relationship of balance and muscle strength in older adults with T2DM has been reported. The ankle plantarflexors and subtalar invertors were reported as the predictors, accounting for $49 \%$ of the TUG performance (Daubney and Culham, 1999). One kilogram increase of ankle dorsiflexor strength could predict 0.4 -sec reduction of the TUG scores among older adults with T2DM (Kraiwong et al., 2019). During swing phase of gait cycle, the ankle dorsiflexors, together with the hip and knee flexors, lift the lower limbs allowing clearance of the toes over the ground (Horak et al., 1989). In older people, the association of TUG scores and knee extensor strength was also evident (Benavent-Caballer et al., 2016). Knee extensor peak torque and the TUG were significantly improved among older adults after 12 weeks exercise compared with the control group (Avelar et al., 2016). For the AST, its tasks also need good movement control as well as the strength of hip flexors and knee extensors (Mian et al., 2007).

ADL was significantly different between groups at 1 year after intervention in this study. The intervention group could maintain their ADL, while the control group gradually declined during the 1-year follow-up. This result showed the same trend in other longitudinal studies which observed deteriorations of ADL and instrumental ADL in older adults (Helvik et al., 2015). Decline in ADL was associated with cognitive impairment, dementia, poor medical health, neuropsychiatric symptoms and being transferred to a nursing home (Helvik et al., 2015). The results might imply that group-based, physical-cognitive training could benefit older adults with T2DM to maintain ADL thus, slowing the disability.

The results of this study showed no significant influence of the intervention on the depression score. This result is consistent with the findings of two previous studies which found no differences of depression scores after 8 and 12 weeks of grouped aerobic exercise among adults with T2DM (Sardar et al., 2014). However, a study reported a reduced depressive symptoms and physical pain in older adults with DM who participated for 12 weeks on the moderateintensity walking program (Alabarse et al., 2019). The possible explanation is that most of our participants had none to mild depressive symptoms which might not be changed by the intervention. This study also excluded participants who had significant pain or musculoskeletal symptoms affecting movements. However, a trend of decreased depression symptoms was observed at 4 weeks after intervention. This might be due to the group-based nature of exercise which encouraged social interaction and participation (Blake et al., 2009).

Fear of falling was detected in both groups and did not differ between groups in our study. Contrast with previous study, 24 sessions of gait and balance exercise alternated with functional strength and endurance exercises for 12 weeks in older adults with T2DM could reduce fear of falling after intervention compared with control group (Allet et al., 2009). Exercise interventions possibly reduced fear of falling to a small to moderate degree immediately postintervention among community-dwelling older people (Kumar et al., 2016). The immediate effect of the intervention on fear of falling was unmonitored, so conclusion could not be drawn. The effect of exercise interventions on fear of falling did not vary by type, frequency, or duration of exercise (Kumar et al., 2016). The key components of exercise to reduce fear of falling remains unclear. Further studies of exercise intervention on fear of falling are needed.

Aligned with a previous study (Boa Sorte Silva et al., 2018b), global cognition did not differ between groups. The physical and cognitive trainings were found to impact cognition (Joubert et al., 2018) with variation of intensity and duration of program (Lauenroth et al., 2016). The cardiovascular and strength training combined with cognitive training of attention and/or executive function/working memory was suggested as an integral part of an effective training program (Lauenroth et al., 2016). Although, the types of physical exercise and cognitive trainings in this study might was aligned which the program suggested (Lauenroth et al., 2016), the effects on cognitive outcomes were not apparent. The training scheme of 1 to 3 hr weekly for 12 to 16 weeks or more was suggested to effect the cognitive performance (Lauenroth et al., 2016). Therefore, the intervention program in this study might not be challenging enough to produce significant improvement. The duration of intervention might also be insufficient to have any significant impact.

The results showed no differences of falls history and falls rate over 1-year follow-up period. Although SSE was reportedly effective in preventing falls by improving balance, preventing fear of falls, and improving perceived health status among older adults (Fisseha et al., 2017), the direct outcome as falls rates was not significantly different. However, a trend of lower falls rates was observed but the sample size of this study might be too small to show the significant effect.

There are some limitations of this study. Only older adults with 
T2DM and balance impairment were included, so the results might not be generalized to the general population. The main outcomes of physical performance, psychological function, and ADL were not monitored through 12 months which limited the marks of the long-term effects of the intervention program. The sample size might also too small to show effectiveness of the intervention program in some outcomes measured.

In conclusion, the group-based, physical-cognitive training of 24 sessions in 8 weeks could reduce risk factors of falls by improving balance and lower limb muscle strength among older adults with T2DM and balance impairment. However, the effects on falls and psychological outcomes were not observed. The results therefore partially suggested an effective strategy to promote active and successful aging specifically the physical aspects.

\section{CONFLICT OF INTEREST}

No potential conflict of interest relevant to this article was reported.

\section{ACKNOWLEDGMENTS}

This study was supported by the Faculty of Physical Therapy, Mahidol University, by a target research grant awarded to RK. We are thankful for the support of participants, local and research staff as well as the coordinators who were extremely helpful in setting up the research stations, recruiting participants, and collecting data.

\section{REFERENCES}

Alabarse SL, Coelho Júnior HJ, Asano RY, Luna Filho B, Santos WC, Oliveira Filho JA. Moderate-Intensity walking training improves depressive symptoms and pain in older adults with good quality of life: a controlled randomized trial. Int J Cardiovasc Sci 2019;32:553-562.

Allet L, Armand S, de Bie RA, Golay A, Monnin D, Aminian K, Staal JB, de Bruin ED. The gait and balance of patients with diabetes can be improved: a randomised controlled trial. Diabetologia 2009;53:458-466.

Avelar BP, Costa JNdA, Safons MP, Dutra MT, Bottaro M, Gobbi S, Tiedemann A, deDavid AC, Lima RM. Balance exercises circuit improves muscle strength, balance, and functional performance in older women. Age (Dordr) 2016;38:14

Benavent-Caballer V, Sendin-Magdalena A, Lison JF, Rosado-Calatayud P, Amer-Cuenca JJ, Salvador-Coloma P, Segura-Orti E. Physical factors underlying the Timed "Up and Go" test in older adults. Geriatr

\section{Nurs 2016;37:122-127.}

Blake H, Mo P, Malik S, Thomas S. How effective are physical activity interventions for alleviating depressive symptoms in older people? A systematic review. Clin Rehabil 2009;23:873-887.

Boa Sorte Silva NC, Gill DP, Gregory MA, Bocti J, Petrella RJ. Multiplemodality exercise and mind-motor training to improve mobility in older adults: a randomized controlled trial. Exp Gerontol 2018a;103: 17-26.

Boa Sorte Silva NC, Gill DP, Owen AM, Liu-Ambrose T, Hachinski V, Shigematsu R, Petrella RJ. Cognitive changes following multiple-modality exercise and mind-motor training in older adults with subjective cognitive complaints: the M4 study. PLoS One 2018b;13:e0196356.

Brooks N, Layne JE, Gordon PL, Roubenoff R, Nelson ME, CastanedaSceppa C. Strength training improves muscle quality and insulin sensitivity in Hispanic older adults with type 2 diabetes. Int J Med Sci 2006;4:19-27.

Chapman A, Meyer C, Renehan E, Hill KD, Browning CJ. Exercise interventions for the improvement of falls-related outcomes among older adults with diabetes mellitus: a systematic review and meta-analyses. J Diabetes Complications 2017;31:631-645.

Colberg SR, Sigal RJ, Yardley JE, Riddell MC, Dunstan DW, Dempsey PC, Horton ES, Castorino K, Tate DF. Physical activity/exercise and diabetes: a position statement of the American Diabetes Association. Diabetes Care 2016;39:2065-2079.

Cooke S, Pennington K, Jones A, Bridle C, Smith MF, Curtis F. Effects of exercise, cognitive, and dual-task interventions on cognition in type 2 diabetes mellitus: a systematic review and meta-analysis. PLoS One 2020;15:e232958.

Daubney ME, Culham EG. Lower-extremity muscle force and balance performance in adults aged 65 years and older. Phys Ther 1999;79: 1177-1185.

Espeland MA, Lipska K, Miller ME, Rushing J, Cohen RA, Verghese J, McDermott MM, King AC, Strotmeyer ES, Blair SN, Pahor M, Reid K, Demons J, Kritchevsky SB. Effects of physical activity intervention on physical and cognitive function in sedentary adults with and without diabetes. J Gerontol A Biol Sci Med Sci 2017;72:861-866.

Feldman EL, Stevens MJ, Thomas PK, Brown MB, Canal N, Greene DA. A practical two-step quantitative clinical and electrophysiological assessment for the diagnosis and staging of diabetic neuropathy. Diabetes Care 1994;17:1281-1289.

Fisseha B, Janakiraman B, Yitayeh A, Ravichandran H. Effect of square stepping exercise for older adults to prevent fall and injury related to fall: systematic review and meta-analysis of current evidences. J Exerc Rehabil 2017;13:23-29.

Helvik AS, Høgseth LD, Bergh S, Šaltytė-Benth J, Kirkevold Ø, Selbæk G. 
A 36-month follow-up of decline in activities of daily living in individuals receiving domiciliary care. BMC Geriatr 2015;15:47.

Hewston P, Deshpande N. Falls and balance impairments in older adults with type 2 diabetes: thinking beyond diabetic peripheral neuropathy. Can J Diabetes 2016;40:6-9.

Hiengkaew V, Saengrueangrob S, Cheawthamai K. A pilot study of a 12week leg exercise and a 6- and 12-month follow-up in communitydwelling diabetic elders: effect on dynamic standing balance. J Med Assoc Thai 2015;98:S60-67.

Horak FB, Shupert C L, Mirka A. Components of postural dyscontrol in the elderly: a review. Neurobiol Aging 1989;10:727-738.

Htut TZC, Hiengkaew V, Jalayondeja C, Vongsirinavarat M. Effects of physical, virtual reality-based, and brain exercise on physical, cognition, and preference in older persons: a randomized controlled trial. Eur Rev Aging Phys Act 2018;15:10.

Joubert C, Chainay H. Aging brain: the effect of combined cognitive and physical training on cognition as compared to cognitive and physical training alone - a systematic review. Clin Interv Aging 2018;13:12671301.

Jung H, Yamasaki M. Association of lower extremity range of motion and muscle strength with physical performance of community-dwelling older women. J Physiol Anthropol 2016;35:30.

Kraiwong R, Vongsirinavarat M, Hiengkaew V, von Heideken Wågert $\mathrm{P}$. Effect of sensory impairment on balance performance and lower limb muscle strength in older adults with type 2 diabetes. Ann Rehabil Med 2019;43:497-508.

Kruse RL, Lemaster JW, Madsen RW. Fall and balance outcomes after an intervention to promote leg strength, balance, and walking in people with diabetic peripheral neuropathy: "feet first" randomized controlled trial. Phys Ther 2010;90:1568-1579.

Kumar A, Delbaere K, Zijlstra GAR, Carpenter H, Iliffe S, Masud T, Skelton D, Morris R, Kendrick D. Exercise for reducing fear of falling in older people living in the community: cochrane systematic review and meta-analysis. Age Ageing 2016;45:345-352.

Lauenroth A, Ioannidis AE, Teichmann B. Influence of combined physical and cognitive training on cognition: a systematic review. BMC Geriatr 2016;16:141.

Lee J, Kim D, Kim C. Resistance training for glycemic control, muscular strength, and lean body mass in old type 2 diabetic patients: a metaanalysis. Diabetes Ther 2017;8:459-473.

Lotrakul M, Sumrithe S, Saipanish R. Reliability and validity of the Thai version of the PHQ-9. BMC Psychiatry 2008;8:46.

Mahoney FI, Barthel DW. Functional evauation: the Barthel index. Md State Med J 1965;14:61-65.

Mentiplay BF, Perraton LG, Bower KJ, Adair B, Pua YH, Williams GP,
McGaw R, Clark RA. Assessment of lower limb muscle strength and power using hand-held and fixed dynamometry: a reliability and validity study. PLoS One 2015;10:e0140822.

Mian OS, Thom JM, Narici MV, Baltzopoulos V. Kinematics of stair descent in young and older adults and the impact of exercise training. Gait Posture 2007;25:9-17.

Morrison S, Colberg SR, Mariano M, Parson HK, Vinik AI. Balance training reduces falls risk in older individuals with type 2 diabetes. Diabetes Care 2010;33:748-750.

Nomura T, Kawae T, Kataoka H, Ikeda Y. Aging, physical activity, and diabetic complications related to loss of muscle strength in patients with type 2 diabetes. Phys Ther Res 2018;21:33-38.

Outayanik B, Carvalho J, Seabra A, Rosenberg E, Krabuanrat C, Chalermputipong S, Suwankan S, Sirisopon N, Rachrujithong P, Thanak W, Sangwipark P. Effects of a physical activity intervention program on nutritional status and health-related physical fitness in Thai older adults: pilot study. Asian J Sports Med 2017;8:e37508.

Pinto TCC, Machado L, Bulgacov TM, Rodrigues-Júnior AL, Costa MLG, Ximenes RCC, Sougey EB. Is the Montreal Cognitive Assessment (MoCA) screening superior to the Mini-Mental State Examination (MMSE) in the detection of mild cognitive impairment (MCI) and Alzheimer's Disease (AD) in the elderly? Int Psychogeriatr 2019;31: 491-504.

Sardar MA, Boghrabadi V, Sohrabi M, Aminzadeh R, Jalalian M. The effects of aerobic exercise training on psychosocial aspects of men with type 2 diabetes mellitus. Glob J Health Sci 2014;6:196-202.

Sherrington C, Michaleff ZA, Fairhall N, Paul SS, Tiedemann A, Whitney J, Cumming RG, Herbert RD, Close JCT, Lord SR. Exercise to prevent falls in older adults: an updated systematic review and meta-analysis. Br J Sports Med 2017;51:1750-1758.

Shumway-Cook A, Brauer S, Woollacott M. Predicting the probability for falls in community-dwelling older adults using the Timed Up \& Go Test. Phys Ther 2000;80:896-903.

Silsupadol P, Shumway-Cook A, Lugade V, van Donkelaar P, Chou LS, Mayr U, Woollacott MH. Effects of single-task versus dual-task training on balance performance in older adults: a double-blind, randomized controlled trial. Arch Phys Med Rehabil 2009;90:381-387.

Strasser B, Pesta D. Resistance training for diabetes prevention and therapy: experimental findings and molecular mechanisms. Biomed Res Int 2013;2013:805217.

Tarnopolsky MA. Mitochondrial DNA shifting in older adults following resistance exercise training. Appl Physiol Nutr Metab 2009;34:348-354.

Thiamwong L, Suwann, J. Effects of simple balance training on balance performance and fear of falling in rural older adults. Int J gerontol 2014;8:143-146. 
Tiedemann A, Shimada H, Sherrington C, Murray S, Lord S. The comparative ability of eight functional mobility tests for predicting falls in community-dwelling older people. Age Ageing 2008;37:430-435.

Venkataraman K, Tai BC, Khoo EYH, Tavintharan S, Chandran K, Hwang SW, Phua MSLA,Wee HL, Koh GCH, Tai ES. Short-term strength and balance training does not improve quality of life but improves functional status in individuals with diabetic peripheral neuropathy: a randomised controlled trial. Diabetologia 2019;62:2200-2210.

Vinik AI, Vinik EJ, Colberg SR, Morrison S. Falls risk in older adults with type 2 diabetes. Clin Geriatr Med 2015;31:89-99, viii.

White IR, Horton NJ, Carpenter J, Pocock SJ. Strategy for intention to treat analysis in randomised trials with missing outcome data. BMJ 2011; 342:d40.

World Health Organization (WHO), Global report on falls prevention in older age. Geneva (Switzerland): WHO Press; 2007.

Yang Y, Hu X, Zhang Q, Zou R. Diabetes mellitus and risk of falls in older adults: a systematic review and meta-analysis. Age Ageing 2016;45: 761-767. 